\title{
Effect of Prenatal Exposure to Progesterone on Dams and Fetus Health in Albino Rats
}

\section{Hala M.Ebaid , Hend M. Tag, Mona A. Higo, Soliman M. T. A. ${ }^{1}$ and Heba M. A. Abdelrazek ${ }^{2}$}

Department of Zoology, Faculty of Science, Suez Canal University, Ismailia, Egypt. ${ }^{1}$ College of Applied Medical Sciences, Department of Medical Laboratory Sciences, University of Bisha, Saudi Arabia, ${ }^{2}$ Department of Physiology, Faculty of Veterinary Medicine, Suez Canal University, Egypt.

\begin{abstract}
This study investigated the effect of progesterone on the pregnant dams health and their offsprings teratology. Eighteen cyclic female rats were used in the study. They introduced to males in the proestrus stage for mating. The pregnant rats were divided into two groups; control group $(\mathrm{n}=9)$ and progesterone-treated group, which given progesterone $10 \mathrm{mg} / \mathrm{kg}$ starting from the first gestation day (GD1) till $19^{\text {th }}$ day of gestation (GD19). The body weight gain of pregnant dams was monitored. The blood biochemical parameters as serum activities of alanine aminotransferase (ALT), alkaline phosphatase (ALP), lactate dehydrogenase (LDH) and Gamma-glutamyl transferase (GGT) as well as the levels of urea and creatinine for dams at GD19. Hepatic malondialdehyde (MDA) and reduced glutathione (GSH) were determined. Serum interleukin-6 (IL-6) and tumor necrosis factor- alpha (TNF- $\alpha$ ) were monitored for dams at GD19. The fetal weight, cervical vertebral length (CVL) and placental weight were recorded. Fetal stain to the skeleton by Alizarin Red S stains was done. Finally histopathological changes for maternal as well as fetal liver and kidney. The treatment with progesterone resulted in significant $(\mathrm{P}<0.05)$ increase in all blood biochemical parameters than control. Hepatic MDA was significantly $(\mathrm{P}<0.05)$ increased however, GSH was reduced $(\mathrm{P}<0.05)$ in progesterone-treated group than control. Serum IL-6 was also increased $(\mathrm{P}<0.05)$ in progesterone-treated dams than control while TNF- $\alpha$ was non significantly altered. Fetal weight and CVL was significantly $(\mathrm{P}<0.05)$ reduced beside the presence of some skeletal malformations in progesterone-treated group while placental weight was non significantly altered. The liver and kidney showed various degrees of retrogressive changes in progesteronetreated group. Progesterone adversely affected mothers' health and their foeti.
\end{abstract}

Keywords: progesterone, rat fetus, biochemical parameters, oxidative stress 


\section{Introduction}

Progesterone (pregn- 4- ene-3, 20dione; abbreviated as P4) is an endogenous steroid hormone involved in the menstrual cycle, pregnancy, and embryogenesis of humans and other species. It belongs to a group of steroid hormones called the progestogens and is the major progestogen in the body (King and Brucker, 2010). P4 exerts its action in target tissues by genomic and nongenomic mechanisms (Brunette and Leclerc, 2001). It modulates the nuclear progesterone receptor (nPR) (King and Brucker, 2010) and membrane progesterone receptors (mPRs) that has been recently discovered (Thomas and Pang, 2012). Usually, $P 4$ nuclear receptors are up regulated by estrogen (Ing and Belen Tornesi, 1997).

Threatened miscarriage in early pregnancy is treated by progesterone in many countries around the world even though there does not seem to be any high-quality studies on the efficacy and safety of this treatment. Few randomized, controlled trials show that women who received progesterone were statistically significantly less likely to have recurrent miscarriages before 34 weeks, to have an infant with a birth weight of $2.5 \mathrm{~kg}$ or lower, or to have an infant diagnosed with intraventricular hemorrhage. However, the usage of progesterone therapy during pregnancy is mandatory in case of threatened abortion, miscarriage and assisted reproductive technologies (Golub et al., 2006).

There are few studied concerning the effect of progesterone on mothers' health and fetal development. Therefore, the current study aims to investigate the effect of progesterone as a source of progesterone in a dose relevant to human exposure on dams' liver and kidney as well as fetal teratology.

\section{Materials and Methods Animals and mating procedures}

Twenty adult females and 4 males, weighing approximately 210-250 g, were purchased from Laboratory Animal House of Faculty of Sciences, Suez Canal University, Egypt. Animals were kept in a standard plastic cage (three rats per cage). They were housed under standard condition maintained at room temperature and under natural daylight rhythm. Animals were kept to acclimatize for 10 days before the onset of the experiment. They were given standard rodent diet ad libitum as well as water supply.

The estrous cycle was checked for regulatory by daily vaginal smear for 2 successive cycles according to procedures of Allen (1922). Vaginal smears were taken from twenty female rats $(n=20)$ once daily at 7:00 am. The smears were dried on flame and methylene blue (Sigma Chemical Co., USA) stained for 2 minutes. The stained smears were examined under a microscope to determine the phases of the estrous cycle. Females with 2 successive 
regular cycles $(n=18)$ were used for this study, while irregular ones $(n=2)$ were excluded. The regular cyclic females in proestrus were kept with males for overnight in the ratio $(3: 1)$. Mating was confirmed by the presence of sperm(s) in the vaginal smears (Piesta et al., 2009).

Experimental design

Eighteen pregnant females were split into 2 groups ( 9 animals per group), Group (I) serves as control; injected with olive oil starting from the first day of gestation. Group (II) injected intramacular with $10 \mathrm{mg} / \mathrm{Kg}$ body weight progesterone $50 \%$ (MARCYRL CO., Germany) in olive oil starting from the first day of gestation. The drug and vehicle were administered intramuscular daily till $19^{\text {th }}$ day of gestation (GD19).

\section{Dams body weight gain}

Mothers body weight of control and treated were recorded at zero day of gestation and at GD19. The body weight gain of mothers was obtained by subtracting the final weight of dams from the initial weight of the same mother.

\section{Blood and tissue sampling}

Blood samples were collected using the orbital sinus technique from retro venous plexus via capillary tube from pregnant dams in plain tubes. The blood sampling was performed under the effect of light diethyl ether anesthesia. After the collection of blood samples, rats were euthanized by an overdose of diethyl ether. The sera were separated from plain tubes at $3000 \mathrm{rpm}$ for $15 \mathrm{~min}$ after blood clotting. The liver and kidney of each rat were excised, washed by the saline solution to remove blood, dried by blotting between filter papers, and divided into two parts. The first part $(0.5 \mathrm{gm}$. of tissue) was perfused with cold $2 \mathrm{ml}$ of $0.15 \mathrm{M}$ $\mathrm{KCl}$ (Liver homogenate and kidney homogenate); liver and kidney homogenates were used for the determination of reduced glutathione (GSH) and lipid peroxidation content. The second part of the dam's liver and kidney tissue as well as Liver and kidney of foeti were preserved in $10 \%$ formalin solution for histopathological examination.

\section{Serum biochemical parameters}

Serum activities of alanine aminotransferase (ALT), alkaline phosphatase (ALP), lactate dehydrogenase (LDH) and Gammaglutamyltransferase (GGT) as well as the levels of urea and creatinine were measured using commercially available kits provided by DIACHEM Ltd., Hungary.

\section{Hepatic malondialdehyde (MDA) and reduced glutathione (GSH}

Lipid peroxidation content in liver homogenate was assessed spectrophotometrically using TBAMDA assay (Hodges et al., 1999). Reduced glutathione hepatic content was measured by the method of Beutler (1963).

Serum interleukin 6 (IL-6) and tumor necrosis factor alpha (TNFa)

Serum IL-6 and TNF- $\alpha$ were measured using commercially 
available ELISA kits provided by Kamiya Biomedical Co. (Cat.No. KT-19418, USA) and ImmunoBiological Laboratories Co., Ltd. (Code no. 27194, Japan), respectively. The procedures were performed according to enclosed pamphlets.

\section{Morphometry and placental weight}

After aeuthanization of the pregnant mothers at GD19, the gravid uteri were carefully examined. The foeti and their placenta were excised from gravid uteri. The placental weight and fetal weights were recorded. Also, the fetal crown- vertebral length (CVL) was estimated via caliber as the distance from Fontanella to the root of tail (Amal et al., 2014). The foeti were carefully examined for any morphological malformations.

\section{Skeletal preparation}

Foeti of each group randomly divided into two parts, first part fixed in $10 \%$ formalin solution for $48 \mathrm{hrs}$. The second part was put in absolute ethyl alcohol. Foeti of both groups were detached from their skin and eviscerated then, preserved in absolute ethyl alcohol for 4 days. Finally, they were stained using Alizarin Red S stain (Astron Chemicals Co., India) according to Green (1952). This technique was used for the treatment of the specimens with a relatively weak solution of potassium hydroxide $(\mathrm{KOH})$ which makes the muscles transparent and helps to limit the stains to bone (Staples, 1964). After staining accomplishment, the stained foeti were transferred to ascending series of glycerol and $2 \%$ aqueous $\mathrm{KOH}$ solution after which they were preserved in $100 \%$ glycerin. The stained preparations were carefully examined under the dissecting binocular microscope to study the different parts of the axial and appendicular skeleton. Photographs were taken for a skeletal system of control and maternally treated fetuses and the abnormalities were recorded.

\section{Histopathology}

Formalin-fixed liver and kidneys of both dams and foeti were dehydrated in alcohol gradient then embedded in paraffin wax. Several 5- $\mu \mathrm{m}$ sections from each sample were cut then stained with hematoxylin and eosin (H\&E) for histopathological examination (Carleton et al., 1980).

\section{Statistical analysis}

The data presented as mean $\pm \mathrm{SE}$. Student T-test was applied for the statistical analysis for the present data of both groups. The result was considered to be significant when $P$ is less than 0.05 (SPSS software, version 16.0; SPSS Inc., Chicago, IL, USA).

\section{Results}

\section{Dams body weight gain}

The dams' body weight gain exhibited significant $\quad(\mathrm{P}<0.05)$ elevation in progesterone $10 \mathrm{mg} / \mathrm{kg}$ treated group than control (Fig. 1).

\section{Serum biochemical parameters}

The serum activities of of ALT, ALP, ADH and GGT as well as the levels of urea, and creatinine exhibited significant $\quad(\mathrm{P}<0.05)$ 
elevation in Progesterone $10 \mathrm{mg} / \mathrm{kg}$ treated mothers (Table 1).

Hepatic and renal malondialdehyde (MDA) and reduced glutathione GSH

Table 1, demonstrated that progesterone $10 \mathrm{mg} / \mathrm{kg}$ treated group exhibited significant $(\mathrm{P}<0.05)$ upregulated MDA level than the control group in both liver and kidney homogenate. Meanwhile, GSH activity revealed significant $(\mathrm{P}<0.05)$ decline in progesterone $10 \mathrm{mg} / \mathrm{kg}$ group than control in both liver and kidney homogenate.

Serum interleukin 6 (IL-6) and tumor necrosis factor alpha (TNFa)

The level of IL-6 exhibited significant $(\mathrm{P}<0.05)$ increment in progesterone- treated group than control animals. The level of TNF- $\alpha$ showed a non-significant difference between the control group and progesterone- treated rats.

Morphometry and placental weight The gravid uteri of Progesterone 10 $\mathrm{mg} / \mathrm{kg}$ group showed unequal distribution of foeti in the 2 horns (Fig. 2). The fetal weight and CVL were significantly $(\mathrm{P}<0.05)$ lower in progesterone $10 \mathrm{mg} / \mathrm{kg}$ group than control. The placental weight exhibited non-significant alterations between the two groups (Table 2).

\section{Skeletal preparation}

Skeletal preparation showed marked incomplete ossification in appendicular skeleton and axial skeleton. The parietal bone, occipital condyles and supraoccipital bone were faintly stained with Alizarin Red S stain in progesterone-treated fetus when compared to normal control (Fig. 3\&4). Also, the absence of metacarpal and metatarsal bones were evident as well as coccygeal vertebrae (Fig. 3) in progesterone treated fetus when compared to normal rats.

\section{Histopathology}

Liver of pregnant rat at GD19 of control group displayed normal architecture of hepatic tissue with normal hepatocytes and central vein. Progesterone- treated pregnant rats showed cloudy swelling of hepatocytes, fibrosis, congested central vein and lymphatic infiltration. The control fetus displayed normal hepatic tissue, central veins, and sinusoids. The fetus liver maternally treated with progesterone, exhibited congested sinusoids (Fig. 5).

The kidney of the pregnant rat at GD19 day displayed normal architecture of renal tissue with normal glomeruli and renal tubules in control pregnant dams. Pregnant dam treated with progesterone, showed cloudy swelling of renal tubules epithelial tissue, degenerated glomeruli, hemorrhage. Control fetus kidney displayed normal renal tissue with normal glomeruli and RT. Fetal kidneys maternally treated with progesterone exhibited atrophied glomeruli beside the presence of necrotic renal tubules (Fig. 6). 


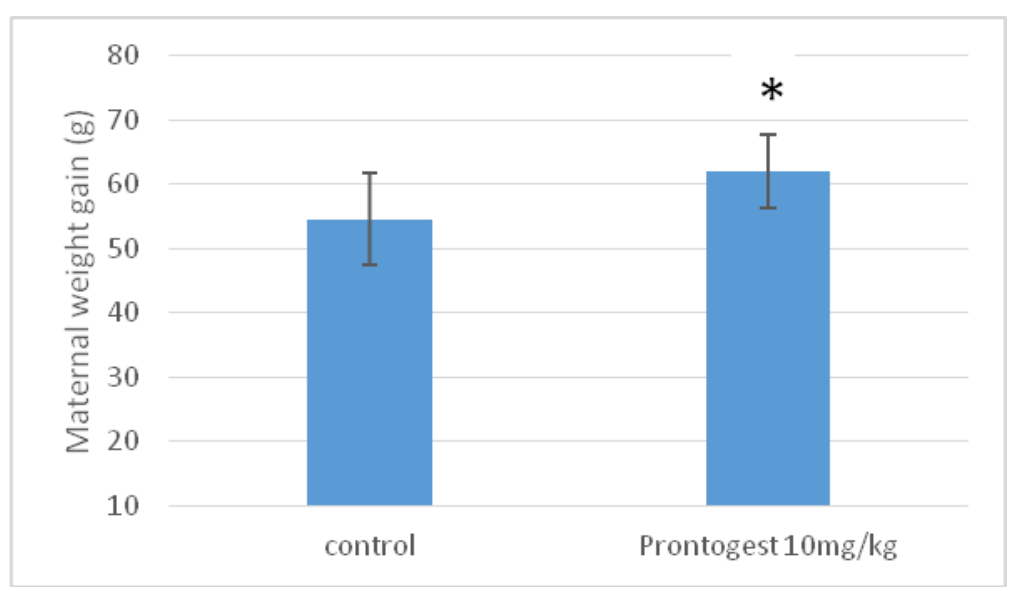

Fig. 1: Effect of progesterone $10 \mathrm{mg} / \mathrm{kg}$ on maternal body weight. Data presented as mean \pm SE.

*Means sigficant difference at $\mathrm{P}<0.05$ as compared to control.

Table (1): Effect of progesterone administration to pregnant albino rats on liver enzymes, renal biomarkers, hepatic and renal GSH and MDA

\begin{tabular}{|l|l|l|}
\hline Parameter/group & Control & Progesterone 10mg/kg \\
\hline ALT(U/L) & $25.00 \pm 0.57$ & $28.66 \pm 0.66^{*}$ \\
\hline ALP (U/L) & $21.00 \pm 0.57$ & $22.66 \pm 0.33^{*}$ \\
\hline LDH (U/L) & $362.66 \pm 3.28$ & $389.66 \pm 3.48^{*}$ \\
\hline GGT (U/L) & $15.66 \pm 0.33$ & $17.00 \pm 0.57^{*}$ \\
\hline Urea (mg/dL) & $17.66 \pm 0.34$ & $19.66 \pm 0.43^{*}$ \\
\hline Creatinine (mg/dL) & $1.00 \pm 0.01$ & $1.09 \pm 0.07$ \\
\hline IL-6 (pg/mL) & $10.00 \pm 0.00$ & $11.66 \pm 0.33^{*}$ \\
\hline TNF- $\alpha$ (pg/mL) & $5.36 \pm 0.38$ & $6.33 \pm 0.40$ \\
\hline Liver MDA (nmole/g tissue) & $0.16 \pm 0.001$ & $0.19 \pm 0.0006^{*}$ \\
\hline Liver GSH (nmole/g tissue) & $40.59 \pm 0.38$ & $33.61 \pm 0.44^{*}$ \\
\hline $\begin{array}{l}\text { Kidney MDA (nmole/g } \\
\text { tissue) }\end{array}$ & $0.14 \pm 0.005$ & $0.16 \pm 0.004^{*}$ \\
\hline $\begin{array}{l}\text { Kidney GSH (nmole/g } \\
\text { tissue) }\end{array}$ & $41.49 \pm 0.97$ & $33.26 \pm 0.68 *$ \\
\hline
\end{tabular}

Data presented as mean \pm SE.

*Means sigficant difference at $\mathrm{P}<0.05$ as compared to control using student $\mathrm{T}$ test. 


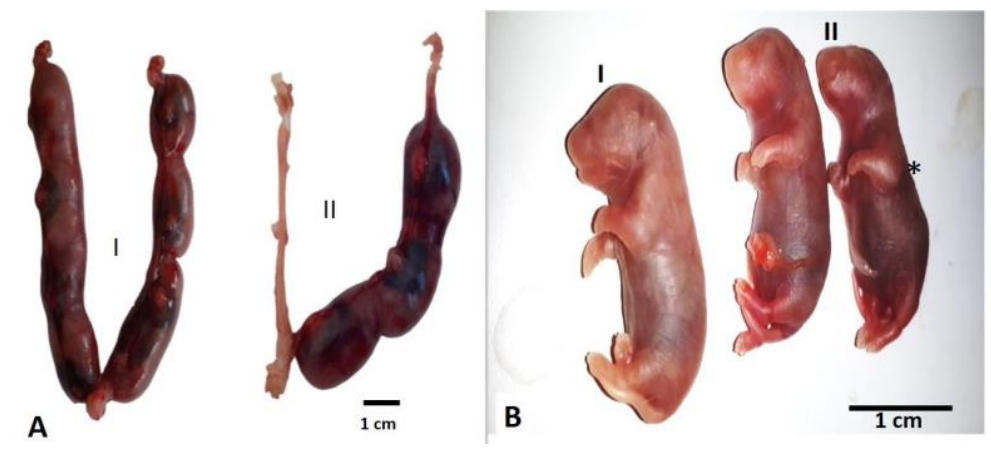

Fig. 2 : (A) gravid uterus of control dams (I) is showing equal distribution of foeti in two horns. The gravid uterus of progesterone $(10 \mathrm{mg} / \mathrm{kg})$ group (II) is showing unequal distribution of foeti in the two horns. (B) photo of control rat fetus (I) showing normal size compared to progesterone- treated group (II) showing reduced size and club hand $(*)$

Table (2):Effect of progesterone administration to pregnant albino rats on fetal weight, CVL and placental weight

\begin{tabular}{|l|l|l|}
\hline Parameter/ group & Control & Progesterone 10mg/kg \\
\hline Fetal weight $(\mathrm{g})$ & $3.95 \pm 0.04$ & $3.18 \pm 0.05^{*}$ \\
\hline Fetal CVL $(\mathrm{Cm})$ & $3.99 \pm 0.01$ & $3.10 \pm 0.02^{*}$ \\
\hline Placental weight $(\mathrm{g})$ & $0.57 \pm 0.013$ & $0.57 \pm 0.013$ \\
\hline
\end{tabular}

Data presented as mean \pm SE.

"Means sigficant difference at $\mathrm{P}<0.05$ as compared to control using student $\mathrm{T}$ test.
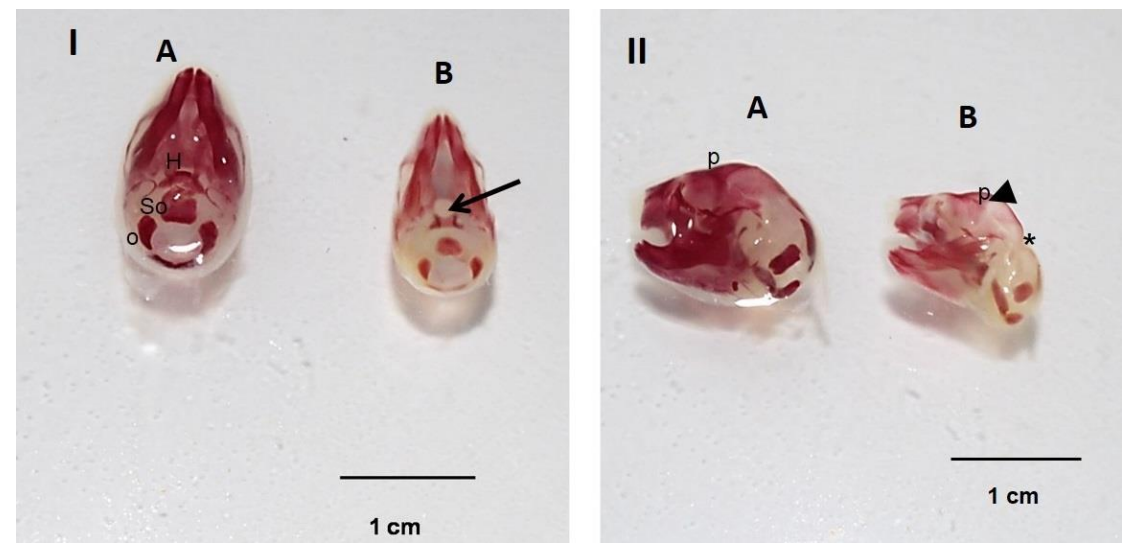

Fig. 3: ( I) Ventral view photograph of fetus skull at GD 19 showing the low bone density of hyoid bone (arrow), occipital condyles and supraoccipital bone (star) in progesterone treated fetus (B) in comparison to normal control (A). (II) Lateral view photograph of parietal bone (p) is faintly stained as well as wide fontanella (star) due to incomplete ossification in progeterone treated fetus (B) in comparison to normal control (A) 

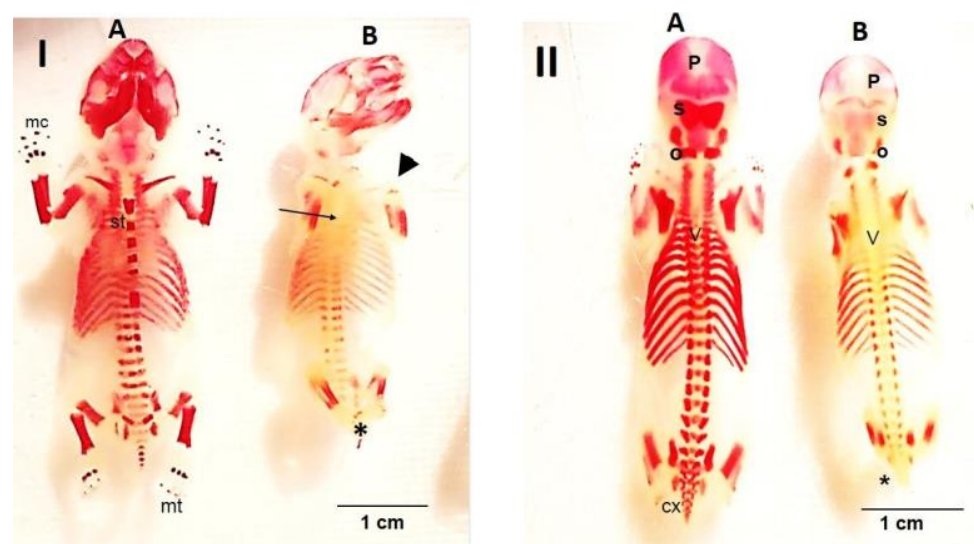

Fig. 4: ( I) Ventral view photograph of whole mount fetus at GD 19 showing the absence of sternebrae (st) (arrow), metacarpal bones (mc) (arrowhead) and metatarsal (mt) (star) in progesterone-treated fetus (B) in comparison to normal control (A).

(II) Dorsal view photograph showing faint ossification of parietal bone (p), occipital (o), supraoccipital bone (s) and vertebrae (v) in progesterone-treated fetus (B) in comparison to normal control (A). Also, coccygeal vertebrae (cx) ossifications were absent (star) in progesterone-treated fetus (B) in comparison to normal control (A).
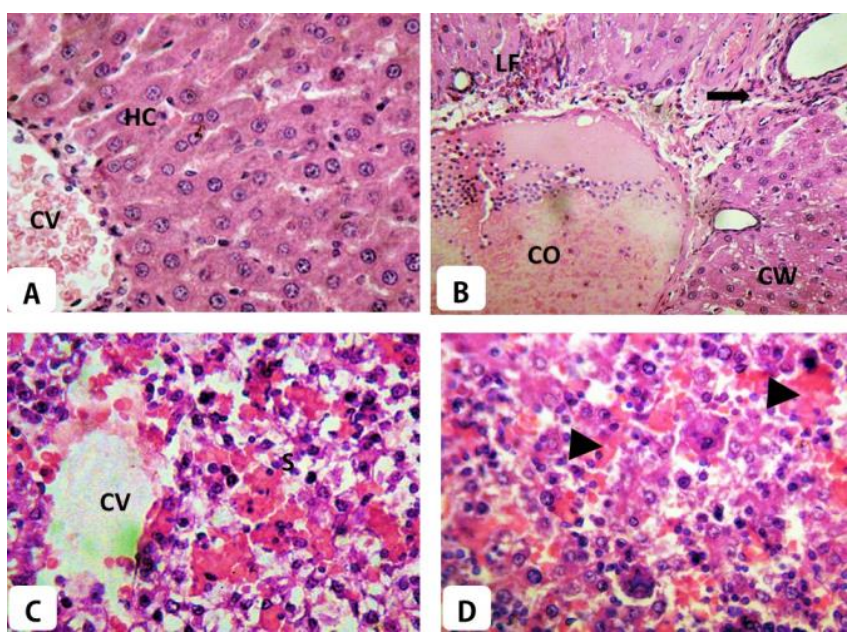

Fig. 5: Liver section of the pregnant rat at GD19 and its fetus: (A) control pregnant rat displayed normal architecture of hepatic tissue with normal hepatocytes (HC) ; (CV) central vein. (B) pregnant rat liver treated with progesterone $10 \mathrm{mg} / \mathrm{kg}$, showed cloudy swelling of hepatocytes $(\mathrm{CW})$, fibrosis (arrow), congested central vein (CO) and lymphatic infiltration (LF). (C) control fetus displayed normal hepatic tissue (CV) central vein; (S) 
sinusoids. (D) fetus liver maternally treated with progesterone $10 \mathrm{mg} / \mathrm{kg}$, exhibited congested sinusoids (head arrows). (magnification, 400X)
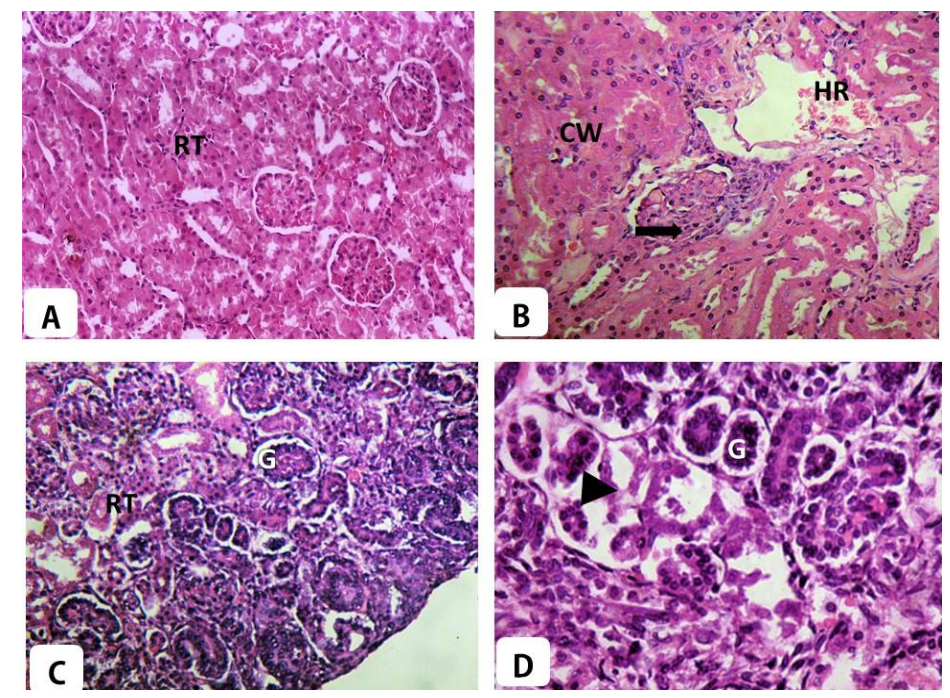

Fig. 6: Kidney section of the pregnant rat at GD19 and its fetus: (A) control pregnant dam displayed normal architecture of renal tissue with normal glomerulus (G); renal tubules (RT). (B) pregnant dam treated with progesterone $10 \mathrm{mg} / \mathrm{kg}$, showed cloudy swelling of renal tubules epithelial tissue (CW), degenerated glomerulus (arrow), hemorrhage (HR). (C) control fetus kidney displayed normal renal tissue (normal glomerulus $(\mathrm{G})$; renal tubules (RT). (D) fetus kidney maternally treated with progesterone $10 \mathrm{mg} / \mathrm{kg}$ exhibited atrophied glomerulus $(\mathrm{G})$ besides necrotic renal tubules (head arrows). (magnification, 200X)

\section{Discussion}

The maternal exposure to progesterone to treat miscarriage and abortion and its adverse effect on maternal health and fetal teratology is not fully discussed or studied. The present research aimed to study the use of progesterone on a dose equivalent to human exposure on maternal health and fetal teratology. The dams exposure to progesterone significantly increased the body weight gain, these results were in agreement with Hervey and Hervey
(1967) while contradicted with those reported by Bruce and Bartholomeusz (1976). These results may be attributed to progesterone influencing effect and body lipid promoting action (Wiegratz and Kuhl, 2006).

Current results revealed a significant increment in activity of ALT in progesterone- treated rats at GD19 than control. These results coincide with Toyoda et al. (2012) who demonstrated that pretreatment with progesterone induced a significant 
$(\mathrm{p}<0.05)$ increase in plasma ALT. However, Rahman and Wendon (2002) found that progesterone couldn't alter ALT activity or reduced it than normal value respectively. The presence of ALT in the plasma here denoting that there were deleterious effects on hepatocytes that lead to their damage and liberation of such enzyme to plasma (Ramaiah, 2007).

Serum ALP was significantly $(p<0.05)$ elevated in progesteronetreated dams than control at GD19. These results were in harmony with Naz et al. (2016) and Suzuki et al. (1980). The increased serum ALP activity could be attributed to the hepatocytes function where the ALP is produced in case of biliary pressure. Moreover, it is closely related to the disturbances in hepatic secretory activities (Giannini et al., 2005; Kumar et al., 2008) as well as the hepatic damage condition.

Serum LDH enzyme was significantly $(\mathrm{p}<0.05)$ elevated in progesterone treaed animals. These results were in accordance with Mizoguchi et al. (2010). LDH could be increased under the condition of lipid peroxidation and oxidative stress and thus leading to increased lactic acid and their salts (Jovanovic et al., 2010). For the hepatic injury, LDH could be considered less specific than ALT (Gitlin and Serio, 1992). The results of LDH augmented the present results concerning elevated the levels of lipid peroxidation and reduced GSH as well as the elevated activities of ALT, ALP and GGT.

The present results revealed a significant $(\mathrm{p}<0.05)$ increase in hepatic and renal MDA content in progesterone-treated dams at the dose $10 \mathrm{mg} / \mathrm{kg}$ than control. These results indicated that progesterone is a casual factor for elevated lipid peroxidation to the membrane of both hepatocytes and renal cells. The elevation of lipid peroxidation suggested that progesterone is injurious for both liver and kidney of pregnant dams that subsequently induced free radicals and oxidative stress (Steller et al., 2018). These results illustrated the observed retrogressive changes in hepatic and renal histopathology. The same trend was found in the current study where GSH was significantly decreased in both liver and kidney homogenate of progesterone-treated dams than control. These results indicated that there is the exhaustion of the antioxidant reserve represented by GSH that confirmed the previous finding of elevated MDA. This may be due to the active metabolism of progesterone to highly reactive compounds and radical that could indicate lipid peroxidation and oxidative stress.

Fedotcheva et al. (2012) stated that among the targets of the steroid hormones are mitochondria, which as the main source of reactive oxygen species (ROS) in the cell play a central role in the development of various pathologies. In contrast to the previous findings 
Sainz et al. (2000) reported no effect of progesterone on liver MDA.

Serum urea was increased in progesterone-treated dams than those of control. These results were similar to those obtained by Matsuo et al. (1986) and Cheung and Lafayette (2013). However, the serum creatinine value showed nonsignificant increment in progesterone treated dams and control ones. These results seemed to be in close similarity with those of Abbassi-Ghanavati et al. (2009). The elevation in serum urea level which is the end product of protein metabolism which is excreted by kidneys

into urine. This indicated that there was impairment in the kidney function (Gowda et al., 2010).

IL-6 was significantly increased in progesterone-treated dams than those of control. IL-6 is considered one of the inflammatory cytokines that denoting an inflammatory or degenerative condition in either liver (Schmidt-Arras and Rose-John, 2016) or kidney (Fielding et al., 2014). It is promoted via ROS can lead to deleterious effects on several processes and disruptions of different cellular components. Among these negative outcomes, the ROS can modulate cytokines expression and activation of redoxsensitive transcription factors AP-1, P53and NF- Kappa B that proceed a cascade of apoptosis mediation (Yoshida et al., 1999).

The present study cleared the adverse effects of maternal progesterone supplementation on the fetal weight and CVL than those of control. These results were parallel to the previous study of Seegmiller et al. (1983) while disagreed with those of Bakry (2013). These results confirmed the adverse effect of progesterone on fetal development and growth however placental weight is not altered. This may be attributed to the ability of progesterone to provoke lipid peroxidation and increase ROS production which subsequently causes DNA damage and so could produce mutations that alter fetal growth and development (Hundal et al., 1997; Schwarz et al., 2009). This data was manifested by the observed renal degeneration and hepatic deteriorations which were observed in the fetal histological sections.

Skeletal defects of foeti prenatally treated with progesterone were observed as delaying in ossification in bones as well as impairment in cartilage formation. These results coincided to Lammer and Cordero (1986) and Bakry (2013). Present data revealed that the prenatal treatment with progesterone can alter bone mineralization and cartilage formation leading to malformations on the skeleton. Moreover, the elevated maternal levels of serum alkaline phosphatase were suggestive for bone catabolic status that could be inferred on fetuses where progesterone had an affinity to cross the placental barrier 
to developing fetus (Kumar and Magon, 2012).

In conclusion, progesterone treatment $10 \mathrm{mg} / \mathrm{kg}$ for pregnant dams seemed to have adverse consequences on hepatic and renal health of pregnant dams. These adverse consequences manifested by increased MDA and decreased GSH that mediated serum proinflammatory cytokine IL-6 which mediated their cell apoptotic effect. The apoptotic effect of progesterone on hepatic and renal tissues of the current study could be sensed by increased their serum enzymes activities as well as deviated histopathological observation that denoting their failure to accomplish their physiological function in the proper way. Also, adverse effects on fetal skeleton and size as well as kidney and liver were noticed.

\section{References}

Abbassi-Ghanavati, M., Greer, L.G., and Cunningham, F.G. (2009: Pregnancy and laboratory studies: a reference table for clinicians. Obstet Gynecol 114, 1326-1331.

Allen, E. (1922): The oestrus cycle in the mouse. Am J Anat 30, 297299.

Amal, M., Abdoon ,A., Ismail, A., Heba, M., Hend, M., and Gihan, G. (2014): Teratogenic Effects of Dietary Genistein and Daidzein are Mediated by Over regulation of Oct4 and Down Regulation of $\mathrm{Cdx} 2$ Expression in Post Implantation Albino Rat Embryos International
Journal of Chemical. Environmental \& Biological Sciences (IJCEBS) Volume 2, 2320-4087

Bakry, S. (2013): Comparative Embryotoxic Effects of Two Injectable Contraceptives, DMPA and Mesocept, in Rats. Journal of Infertility and Reproductive Biology 1, 74-86.

Beutler ,E. (1963): Improved method for the determination of blood glutathione. J Lab Clin Med 61, 882-888.

Bruce, N.W., and Bartholomeusz, R.K. (1976): Effects of Maternal Progesterone Supplementation on Fetal, Placental and Corpus Luteal Weights in the Rat. Biology of Reproduction 15, 84-89.

Brunette, M., and Leclerc, M. (2001): Effect of estrogen on calcium and sodium transport by the nephron luminal membranes. Journal of endocrinology 170,441 450.

Carleton, H.M., Drury, R.A.B., and Wallington, E.A (1980): Carleton's histological technique (Oxford University Press, USA).

Cheung, K.L., and Lafayette, R.A. (2013): Renal Physiology of Pregnancy. Advances in Chronic Kidney Disease 20, 209-214. Fedotcheva, T.A., Kruglov, A.G., Teplova, V.V., Fedotcheva, N.I., Rzheznikov, V.M., and Shimanovskii, N.L. (2012): Effect of steroid hormones on production of reactive oxygen species in mitochondria. Biophysics 57, 792795 . 
Fielding, C.A., Jones, G.W., Jones, S.A., and Fraser, D.J. (2014): Interleukin-6 in renal disease and therapy. Nephrology Dialysis Transplantation 30, 564-574.

Giannini, E.G., Testa, R., and Savarino, V. (2005): Liver enzyme alteration: a guide for clinicians. Canadian Medical Association Journal 172, 367-379.

Gitlin, N., and Serio, K.M. (1992): Ischemic hepatitis: widening horizons. . American Journal Of Gastroenterology 87.

Golub, M.S., Kaufman, F.L., Campbell, M.A., Li, L.H., and Donald, J.M. (2006): "Natural" progesterone: information on fetal effects. Birth Defects Research Part B: Developmental and Reproductive Toxicology 77, 455-470.

Gowda, S., Desai, P.B., Kulkarni, S.S., Hull, V.V., Math, A.A.K., and Vernekar, S.N. (2010): Markers of renal function tests. North American journal of medical sciences 2, 170173.

Green, M.C. (1952): A rapid method for clearing and staining specimens for the demonstration of bone.

Hervey, E., and Hervey, G. (1967): The effects of progesterone on body weight and composition in the rat. Journal of Endocrinology 37, 361384.

Hodges, D.M., DeLong, J.M., Forney, C.F., and Prange, R.K. (1999): Improving the thiobarbituric acid-reactive-substances assay for estimating lipid peroxidation in plant tissues containing anthocyanin and other interfering compounds. Planta 207, 604-611.

Hundal, B.S., Dhillon, V.S., and Sidhu, I.S (1997): Genotoxic potential of estrogens. Mutation Research/Genetic Toxicology and Environmental Mutagenesis 389, 173-181.

Ing, N.H., and Belen Tornesi, M. (1997): Estradiol up-regulates estrogen receptor and progesterone receptor gene expression in specific ovine uterine cells. Biology of reproduction 56, 1205-1215.

Jovanovic, P., Zoric, L., Stefanovic, I., Dzunic, B., Djordjevic-Jocic, J., Radenkovic, M., and Jovanovic, M. (2010): Lactate dehydrogenase and oxidative stress activity in primary open-angle glaucoma aqueous humour. BosnianJournal of Basic Medical Sciences 10, 83-88.

King, T.L., and Brucker, M.C. (2010): Pharmacology for women's health (Jones \& Bartlett Publishers).

Kumar, P., and Magon, N. (2012): Hormones in pregnancy. Nigerian medical journal : journal of the Nigeria Medical Association 53, 179-183.

Kumar, R.S., Manivannan, R., Balasubramaniam, A., and Rajkapoor, B. (2008). Antioxidant and hepatoprotective activity of ethanol extract of Indigofera trita Linn. on $\mathrm{CCl} 4$ induced hepatotoxicity in rats. J Pharmacol Toxicol 3, 344-350.

Lammer, E.J., and Cordero, J.F. (1986): Exogenous Sex Hormone Exposure and the Risk for Major 
Malformations. JAMA 255, 31283132.

Matsuo, M., Morikawa, Y., Hashimoto, Y., and Baratz, R.S. (1986): Changes in blood urea nitrogen (BUN) concentration during pregnancy in the rat with or without obstructive uremia. Experimental pathology 30, 203208.

Mizoguchi, Y., Matsuoka, T., Mizuguchi, H., Endoh, T., Kamata, R., Fukuda, K., Ishikawa, T., and Asano, Y. (2010): Changes in blood parameters in New Zealand White rabbits during pregnancy. Laboratory animals 44, 33-39.

Naz, F., Jyoti, S., Rahul, Akhtar, N., and Siddique, Y.H. (2016): Effect of Oral Contraceptive Pills on the Blood Serum Enzymes and DNA Damage in Lymphocytes Among Users. Indian journal of clinical biochemistry : IJCB 31, 294-301.

Piesta, A., Maj, T., and ChełmońskaSoyta, A. (2009): The influence of mating on estrogen receptor alpha protein level in spleen and uterine macrophages in female mice. Reproductive Biology 9, 225-240.

Rahman, T.M., and Wendon, J. (2002): Severe hepatic dysfunction in pregnancy. QJM: An International Journal of Medicine 95, 343-357.

Ramaiah, S.K. (2007): A toxicologist guide to the diagnostic interpretation of hepatic biochemical parameters. Food and Chemical Toxicology 45, 1551-1557.

Sainz, R.M., Reiter, R.J., Mayo, J.C., Cabrera, J., Tan, D.X., Qi, W., and Garcia, J.J. (2000): Changes in lipid peroxidation during pregnancy and after delivery in rats: effect of pinealectomy. Journal of Reproduction and Fertility 119, 143149.

Schmidt-Arras, D., and Rose-John, S. (2016): IL-6 pathway in the liver: From physiopathology to therapy. Journal of Hepatology 64, 14031415.

Schwarz, E.B., Hess, R., and Trussell, J. (2009): Contraception for Cancer Survivors. Journal of General Internal Medicine 24, 401406.

Seegmiller, R.E., Nelson, G.W., and Johnson, C.K. (1983): Evaluation of the teratogenic potential of Delalutin (17 $\alpha$-hydroxyprogesterone caproate) in mice. Teratology 28, 201-208.

Staples, R.E. (1964): Refinements in rapid clearing technic in the $\mathrm{KOH}-$ alizarin red $\mathrm{S}$ method for fetal bone. Stain Technol 39, 61-63.

Steller, J., Alberts, J., and Ronca, A. (2018): Oxidative Stress as Cause, Consequence, or Biomarker of Altered Female Reproduction and Development in the Space Environment. International journal of molecular sciences 19, 3729 .

Suzuki, M., Kuramoto, H., Hamano, M., Shirane, H., and Watanabe, K. (1980): Effects of oestradiol and progesterone on the alkaline phosphatase activity of a human endometrial cancer cellline. Acta Endocrinol 93, 108-113.

Thomas, P., and Pang, Y. (2012): Membrane progesterone receptors: evidence for neuroprotective, neurosteroid signaling and 
neuroendocrine functions in progestogens. The European Journal neuronal cells. Neuroendocrinology $96,162-171$.

of Contraception \& Reproductive Toyoda, Y., Endo, S., Tsuneyama, Health Care 11, 153-161.

K., Miyashita, T., Yano, A., Fukami, Yoshida, Y., Maruyama, M., Fujita, T., Arai, N., Hayashi, R., Araya, J., T., Nakajima, M., and Yokoi, T. (2012): Mechanism of Exacerbative Effect of Progesterone on DrugInduced Liver Injury. Toxicological Sciences 126, 16-27. Matsui, S., Yamashita, N., Sugiyama, E , and Kobayashi, M. (1999: Reactive oxygen intermediates stimulate interleukin-6 production in human bronchial Wiegratz, I., and Kuhl, H. (2006): Metabolic and clinical effects of epithelial cells. Am J Physiol 276 900-908. 


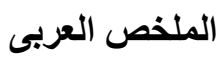

تأثثر التعرض قبل الولادة للبروجسترون على صحة الامهات و الاجنة في الجرذان البيضاء

هالة محمد عبيد" هند معروف تاج " منى حجو'،محمد طلعت سليمان"، هبة محمد عبد الرازق "

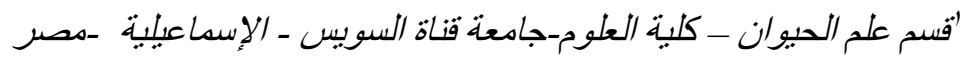

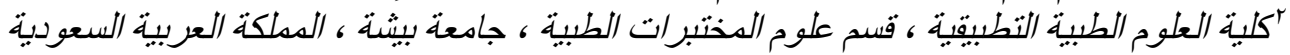

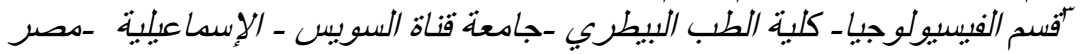

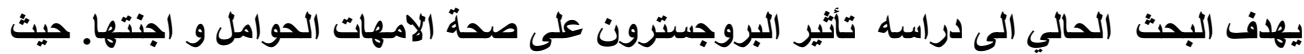

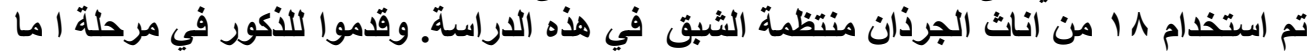

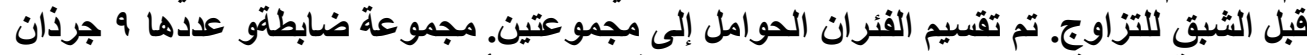

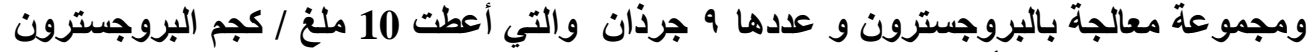

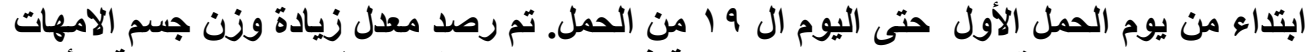

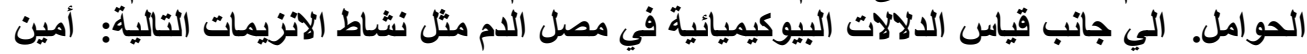

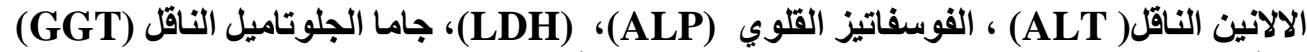

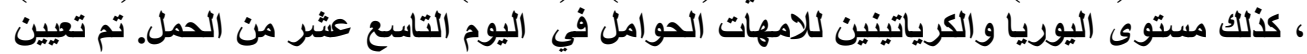

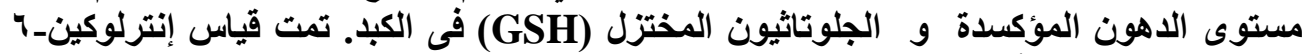

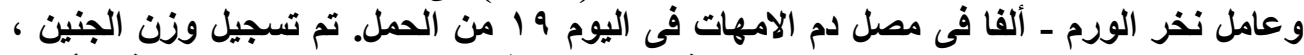

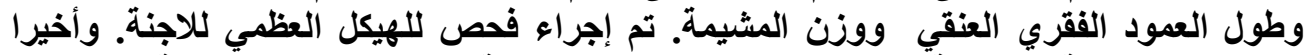

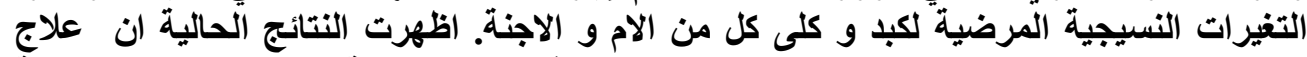

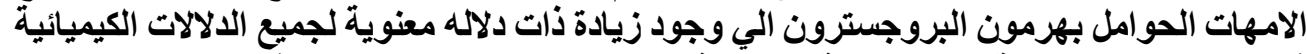

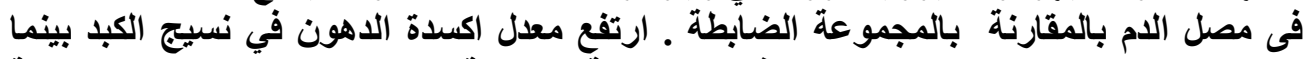

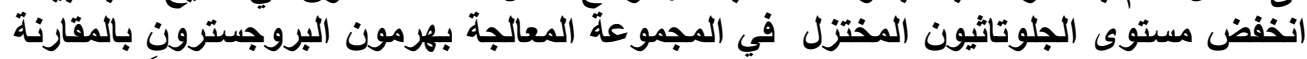

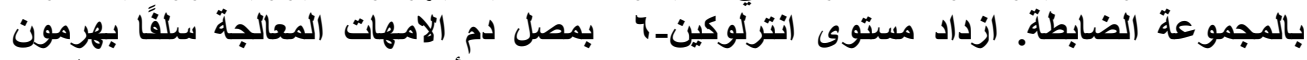

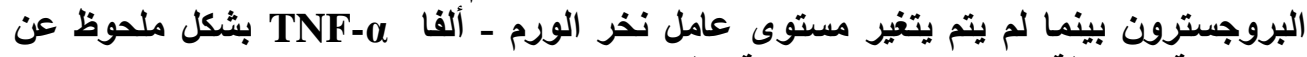

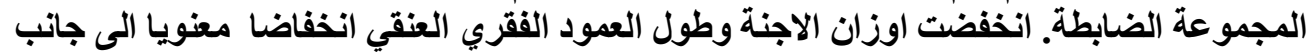

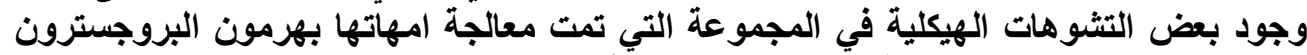

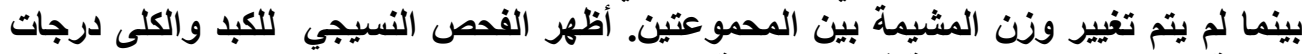

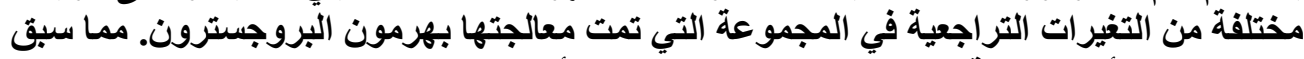

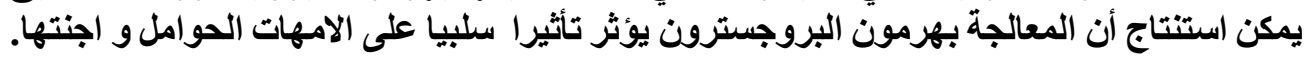

